\title{
O desempenho no trabalho dos educadores canadenses: o peso relativo da tarefa, as condições de ensino e as relações entre alunos e equipe pedagógica
}

\section{The job performance of Canadian educators: the relative importance of the task, teaching conditions and relations between students and teaching team}

\author{
Claude Lessard ${ }^{1}$ \\ Pierre Canisius Kamanzi ${ }^{2}$ \\ Mylène Larochelle ${ }^{3}$
}

\begin{abstract}
RESUMO
A evolução tanto da população escolar quanto das numerosas responsabilidades do papel do educador incita os pesquisadores a questionarem sobre o estado do corpo docente. Neste artigo, a partir de dados empíricos recentes obtidos entre os educadores canadenses (2006), nos interessamos pelo desempenho dos educadores nesse trabalho complexo e em plena evolução que é o ensino, como também pelos fatores que explicam sua variação. De modo geral, os resultados obtidos mostram que o rendimento do trabalho dos educadores está associado de modo significativo à carga de trabalho e
\end{abstract}

1 Pesquisador do Centre de Recherche Interuniversitaire sur La Formation et la Profession Enseignante (CRIFPE) - Montreal. Titular da Cadeira de Pesquisa da Universidade de Montreal sobre os trabalhos da Área de Educação. Faculdade das Ciências da Educação - Universidade de Montreal. C.E.P. 6128, Centro, Montreal (Québec) H3C 3J7. Email: claude.lessard@umontreal.ca

2 Agente de Pesquisa (CRIFPE). Cadeira de Pesquisa da Universidade de Montreal sobre os trabalhos da Área de Educação. Faculdade das Ciências da Educação - Universidade de Montreal, C.E.P. 6128, Centro, Montreal (Québec) H3C 3J7. E-mail: pierre.canisius.kamanzi@umontreal.ca

3 Agente de Pesquisa (CRIFPE). Cadeira de Pesquisa da Universidade de Montreal sobre os trabalhos da Área de Educação. Faculdade das Ciências da Educação - Universidade de Montreal, C.E.P. 6128, Centro, Montreal (Québec) H3C 3J7. E-mail: mylene.larochelle@umontreal.ca 
às condições de trabalho, mas também igualmente às relações sociais que cercam o exercício cotidiano da profissão. O exame atento dos resultados nos leva a concluir que a influência das relações sociais é mais importante que aquela das condições de trabalho. Mais particularmente, as relações com os alunos exercem uma influência claramente mais significativa que outros fatores estudados: quanto mais as relações são gratificantes, ao menos segundo a percepção dos educadores, mais os professores têm a tendência de atribuir um desempenho positivo à profissão. E, por outro lado, as relações difíceis com os alunos têm um efeito nefasto sobre a experiência profissional dos educadores. O mesmo se dá, ainda que em menor grau, no que se refere à qualidade das relações com os outros membros da equipe pedagógica.

Palavras-chave: desempenho no trabalho; tarefa; condições de ensino; status profissional; relação com alunos.

\begin{abstract}
The school population evolution and the many new tasks under teacher responsibilities encourage researchers to question about the teachers' status and conditions. In this article, based on empirical data gathered from Canadian educators (2006), we are concerned about the performance of educators in this complex and evolving work called teaching, but also we're looking for factors that explain its variation. Overall, the results show that the performance of educators' work is significantly associated with the workload and working conditions but also the social relationships that surround the daily exercise of the profession. Careful examination of the results leads us to conclude that the influence of social relationships is more important than working conditions. More particularly, relations with students exert an influence much more significant than other factors studied: the more relationships are rewarding, at least as perceived by the teachers, the more teachers have the tendency to attribute positive performance to their profession. And, on the other hand, difficult relations with students have an adverse effect on the professional experience of the educators. The same is true, albeit to a lesser extent, with regard to the quality of relationships with other members of the teaching team.

Keywords: job performance; task; teaching conditions; professional status; relationship with students.
\end{abstract}




\section{Introdução}

É relativamente banal afirmar que o ensino se tornou, desde a massificação e a democratização dos sistemas educacionais, um trabalho mais difícil que antes. Alguns afirmam até que se trata de um trabalho "impossível" (BOUMARD, 1992). Ainda que haja nesse discurso certa idealização do passado que os historiadores da educação provavelmente não compartilhariam (PROST, 1968), uma visão de uma era de ouro em que a autoridade do mestre era incontestável e em que os alunos pareciam mostrar apetite pelo saber e aquiescência pela disciplina escolar, uma vasta literatura científica internacional (OCDE, 2005) documentou as reais dificuldades contemporâneas da profissão, principalmente no ensino médio, em um meio sociocultural difícil e próximo de uma população escolar cada vez mais diversificada e culturalmente plural. Vários pesquisadores se debruçaram sobre a crise educacional (BOURDONCLE; DEMAILLY, 1998; MAROY, 2006), o abandono voluntário (INGERSOLL, 2001; JOHNSON et al., 2005; OCDE, 2005), sobre o estresse no ensino e o esgotamento profissional - também chamado de "burnout" (MASLACH; JACKSON, 1986) -, sobre a violência verbal e física dirigida contra os educadores, sobre as provações da profissão (BARRÈRE, 2002) e sobre o sofrimento dos educadores (LANTHEAUME, 2007; HÉLOU; LANTHEAUME, 2008).

Escreveu-se muito sobre a evolução do papel dos educadores e sua complexidade. Foi assim que a OCDE, em um relatório, O papel crucial dos educadores: Atrair, formar e manter educadores de qualidade (2005), descreve as expectativas cada vez mais complexas que as escolas e os educadores devem satisfazer. De fato, o papel do educador evoluiu e a sociedade contemporânea espera que os estabelecimentos escolares e os educadores que trabalham ali cotidianamente sejam capazes de assumir eficazmente os alunos vindos de meios sociais e linguísticos diferentes, de lutar eficazmente contra a reprovação escolar, sejam capazes de se mostrar sensíveis às questões culturais e aos problemas de igualdade dos sexos, de encorajar a tolerância e a coesão social, de se ocupar dos alunos desfavorecidos e dos alunos que apresentam dificuldades de aprendizado e problemas de comportamento, que sejam capazes de usar novas tecnologias da informação e comunicação, de se informar sobre novas áreas do conhecimento e novos métodos de ensino e avaliação, e que sejam capazes de adotar pedagogias modernas, eficazes e diferenciadas (PERRENOUD, 1995 e 1997) etc. A fim de responder às exigências da sociedade e da economia do saber, os educadores devem ser capazes de desenvolver a autonomia e o interesse dos alunos em prosseguir com a aprendizagem ao longo de suas vidas. 
A evolução tanto da população escolar quanto das inúmeras responsabilidades que decorrem da evolução do papel de educador incita os pesquisadores a perguntarem sobre o estado do corpo docente. Neste artigo, a partir de dados empíricos e recentes recolhidos entre os educadores canadenses (2006), nos interessamos tanto pela relação dos educadores com esse trabalho complexo e em plena evolução, como também pelos fatores que explicam a sua variação. Antes de apresentar nosso modelo de análise e os resultados, seguiremos com uma abordagem dos estudos disponíveis sobre a questão.

\section{Levantamento dos trabalhos escritos}

Os escritos pertinentes que trazem resultados de pesquisas empíricas e que utilizam dados comparáveis aos nossos (i.e. dados quantitativos) tratam da satisfação no trabalho, do engajamento profissional e da vontade de permanecer ou deixar o ensino.

A temática da retenção na profissão ou, ao contrário, das partidas do ensino tomou importância nesses últimos anos, como bem corrobora isso um relatório da OCDE (2005). Esses escritos sobre o abandono ou a partida voluntária do ensino merecem ser contados, o desejo de deixar o ensino sendo considerado como uma medida indireta do desempenho no trabalho ou da satisfação "global" sobre o ensino. E mais, vários pesquisadores estimam que essa medida seja mais interessante que a declaração "oficial" da satisfação, estando esta última sujeita a diversas formas de desejo social.

Segundo os autores do relatório da OCDE (2005), além de salientar o interesse pelo salário, os educadores atribuem muita importância à relação que eles têm com seus alunos e colegas, ao apoio do superior, às boas condições de trabalho, à satisfação e à gratificação profissional, ao avanço na carreira como também às possibilidades de aperfeiçoamento. De sua parte, Ingersoll (2001) encontrou um conjunto de fatores responsáveis por uma alta da "rotatividade" dos educadores americanos: salário baixo, apoio inadequado da administração escolar, alunos indisciplinados e também pouca participação na tomada de decisões por parte dos educadores. Assim, é preciso mencionar que os salários variam consideravelmente de um Estado a outro nos Estados-Unidos, e até mesmo de um distrito escolar a outro.

Nos escritos de Johnson et al. (2005), os resultados de pesquisa relatados indicam que a decisão dos educadores de permanecer em sua escola ou na profissão é influenciada por uma combinação de recompensas intrínsecas e 
extrínsecas que eles obtêm do trabalho. As recompensas intrínsecas incluem o prazer que eles têm junto às crianças, a contribuição gratificante no aprendizado dos alunos, a alegria de ensinar um assunto de que gostam ou a oportunidade de desenvolver novas habilidades. As recompensas extrínsecas compreendem o salário, a renda da aposentadoria, os prêmios, um reconhecimento público de sua função ou o fato de ter sido escolhido para assumir responsabilidades particulares. Além disso, certas condições de trabalho fazem com que a experiência de trabalhar seja prazerosa ou menos agradável: ter uma sala bem iluminada, uma ventilação adequada ou um estacionamento seguro a fim de poder trabalhar até tarde da noite sem preocupações. Certas condições de trabalho positivas podem compensar condições negativas (como, por exemplo, a falta de material, colegas problemáticos ou uma classe numerosa). Em certas situações, os aspectos negativos se sobrepõem aos positivos e levam os educadores a deixar a profissão.

Segundo o relatório da OCDE (2005), na Inglaterra, entre as razões levantadas pelos educadores que deixaram o ensino em 2002 (além da aposentadoria), as condições de trabalho exaustivas estão em primeiro lugar. Na verdade, uma "carga de trabalho pesada demais" é a justificativa para deixar a profissão para $52 \%$ dos professores do ensino fundamental e $39 \%$ do ensino médio. Os fatores que têm mais peso são as "iniciativas governamentais", com $39 \%$ dos educadores do ensino fundamental e $35 \%$ do médio, o "estresse", para $37 \%$ dos educadores do ensino fundamental e $34 \%$ do ensino médio, e o "mau comportamento dos alunos", para 34\% dos professores do ensino médio. Os autores do relatório salientam que uma imagem se destaca entre as razões colocadas pelos educadores para deixar sua profissão: os fatores ligados à carreira ("atraídos por outro emprego", "melhores perspectivas de carreira", "tratamento muito fraco", "ter uma oferta de trabalho melhor remunerado"), os quais têm mais importância para os educadores do ensino médio, enquanto que os educadores do ensino fundamental atribuem mais valor às condições de trabalho ("carga de trabalho pesada demais", "iniciativas governamentais", "estresse") (OCDE, 2005). O relatório nacional da Suíça apresenta resultados semelhantes, enquanto que os autores do relatório da comunidade flamenga da Bélgica salientam os efeitos de várias reformas educacionais ocorridas ao longo dos últimos dez anos.

Ainda que as razões para a partida variem ligeiramente de um país a outro, com exceção da oferta de outro emprego e de razões pessoais, são as más condições de trabalho que causam o abandono da profissão (carga de trabalho pesada ou excessiva, falta de recursos e de apoio, gestão complicada de alunos e pais) (OCDE, 2005). E mais, segundo Mulford (2003), "a direção das escolas tem um papel importante na permanência dos educadores contribuindo com a promoção e manutenção de um ambiente estimulante, uma cultura de solidariedade, como um efeito tampão entre os educadores e a pressão crescente e por 
vezes contraditória vinda do exterior" (OCDE, 2005, p. 218). O sentimento de pertencimento a uma escola, o apoio ao trabalho, a determinação nas tarefas etc., são elementos que a direção pode favorecer.

Os estudos elencados até aqui listam certo número de fatores associados ao "mal-estar" no ensino, à insatisfação no trabalho e à vontade de deixar a profissão. Mas esses estudos não permitem estimar a importância relativa disso, o que seria essencial se quiséssemos tirar dali algumas ações para uma política educativa eficazmente orientada para a melhoria da "condição de ensino". Abordaremos nos parágrafos seguintes alguns estudos que procedem a essa ponderação.

No Canadá, King e Peart (1992, p. 154-156), a partir de uma análise de regressão, mostraram que os fatores que determinam a satisfação no trabalho são, em ordem de importância, em primeiro lugar, a relação positiva com os alunos e administradores, considerada muito importante; em seguida, a relação positiva com colegas e projetos normais de aposentadoria, de importância moderada, enquanto que o gênero é considerado mais ou menos importante, assim como o fato de que o ensino tenha sido a primeira escolha como carreira ou que o absentismo ao trabalho seja fraco. Em suma, se vários fatores têm uma relação significativa com a satisfação (como o gênero, com as mulheres tendo um nível mais elevado de satisfação no trabalho do que os homens), eles aparecem claramente menos determinantes que a qualidade das relações em sala de aula e na escola.

King e Peart (1992) mediram também o estresse no trabalho e suas causas. Sua análise de regressão mostra que os problemas com os alunos, a má relação com os administradores escolares, assim como a carga de trabalho excessiva após a aula (correção e preparação de aulas) têm um efeito moderadamente importante sobre o estresse no ensino, como foi relatado pelos próprios educadores.

Aliás, estudos repetidos (2001 e 2005) da Federação Canadense de Educadores revelam que os educadores, depois de interrogados sobre isso, têm claramente o sentimento de que a carga de trabalho aumentou consideravelmente ao longo da última década, enquanto que sua autonomia profissional diminuiu sobretudo no que se refere ao currículo de avaliações dos alunos, e também no contexto organizacional, em que a administração procura colocar em prática dispositivos de avaliação dos educadores.

O estudo de Maroy (2002) sobre a satisfação profissional dos educadores da comunidade francesa da Bélgica se mostra pertinente ao nosso propósito. Ele comporta informações sobre a condição do ensino belga contemporâneo, dados sobre a satisfação no trabalho, suas diferentes dimensões ou componentes, assim como seus determinantes. O autor reagrupa diferentes aspectos da profissão em cinco grandes categorias: o conteúdo do trabalho (relações com os alunos, interesse pela matéria, a pedagogia, a autonomia), as características 
associadas ao emprego (salário, possibilidade de carreira, segurança, tempo livre, equilíbrio entre vida profissional e privada), o estabelecimento e a posição da profissão na sociedade. Os resultados revelam que a satisfação profissional dos educadores belgas varia segundo as cinco categorias: ela é maior no que se refere ao conteúdo do trabalho, ao tipo e nível do ensino e às relações no estabelecimento; ela é mais problemática para as características do emprego e se mostra negativa quanto à posição da profissão na sociedade.

A satisfação é relativamente elevada, ainda que uma proporção um tanto significativa de educadores se declare insatisfeita: por exemplo, perto de um quinto dos educadores se dizem prontos a deixar o ensino, e "mais ainda, educadores, mais ou menos insatisfeitos, estão no meio do caminho, prontos a deixar seus empregos, ao menos parcialmente" (MAROY, 2002, p.165). Maroy constata também que os educadores estão menos satisfeitos do que o conjunto de trabalhadores belgas.

Esse pesquisador procedeu também às análises de regressão para quatro de suas categorias a fim de identificar e ponderar seus determinantes. Ele constata que a dificuldade do trabalho escolar com os alunos, um índice de frequência dos problemas de disciplina, como também índices de degradação das relações entre colegas e com o diretor do estabelecimento se mostram como sendo os melhores predicadores da satisfação, enquanto que um elemento como o número de alunos por turma não teve muito efeito. O autor observa: "não é tanto o número de alunos que causa problemas, mas suas atitudes e comportamentos com relação à escolaridade" (MAROY, 2002, p. 159).

Com essa análise, Maroy conclui assim:

O que podemos reter dessas regressões que buscam dar conta da variação da satisfação profissional? Elas demonstram primeiramente que as condições concretas em que trabalha o educador têm um papel chave na explicação. No entanto, nessa "condição de ensino", não são as "condições materiais" que contam (a variável tem pouca ou nenhuma importância); são essencialmente as características relativas às atitudes dos alunos (sobretudo aquelas que condicionam a dificuldade do trabalho educacional ou a frequência dos problemas disciplinares) e o estado das relações sociais no estabelecimento que são determinantes (2002, p. 162).

No plano das implicações políticas desses resultados, Maroy reflete sobre as dimensões intrínsecas e extrínsecas da satisfação no trabalho. Já que a insatisfação se dá principalmente nas dimensões extrínsecas (salário, carreira, posição na sociedade), ao passo que a satisfação está sobretudo associada ao conteúdo 
do trabalho e às relações sociais (com os alunos, colegas e direção), poderíamos pensar que seria necessário que as autoridades bonificassem as dimensões extrínsecas, indo ao encontro, assim, de certa reivindicação educacional. Entretanto, Maroy teme que dessa maneira não se legitime uma lógica de compensação mais "extrínseca" (portanto de injunção de recursos financeiros e materiais no sistema educativo) sem que se aprimore a dimensão "intrínseca" que, no entanto, se mostra mais problemática para muitos, principalmente por causa da evolução das características e das disposições dos alunos. Maroy preconiza

refletir sobre as condições sociais de uma real profissionalização dos educadores, o que acentuaria seu poder coletivo, a tomada de responsabilidade (empowerment) individual e coletiva dos educadores que procede de uma vontade de dar mais lugar à palavra coletiva dos educadores, principalmente no que se refere às escolhas organizacionais e pedagógicas dos estabelecimentos (2002, p. 169).

Existem, portanto, indicações relativamente claras de que o desempenho no trabalho dos educadores é influenciado não apenas por um fator, mas por vários, dentre os quais a qualidade nas relações sociais (com os alunos, a direção e os colegas) se mostra muito importante e até mais do que as "condições materiais" ou de emprego. Vejamos se nossos dados corroboram esses resultados que, aliás, são congruentes com a natureza fundamentalmente interativa do ensino (TARDIF; LESSARD, 1999). Mas, antes, alguns esclarecimentos conceituais são necessários.

\section{Trabalho educacional e desempenho na profissão}

Em uma obra em que um de nós contribuiu (TARDIF; LESSARD, 1999), propusemos estudar o trabalho educacional a partir de três entradas complementares e interdependentes. Essas três dimensões do trabalho são a atividade, o status e a experiência. A atividade concerne o que fazem os educadores, sobretudo em aula, mas também na escola e na "comunidade"; essa atividade, quando observada e analisada, deve ser entendida em uma confrontação entre a tarefa prescrita pela instituição, as obrigações compreendidas da situação e as visões e projetos do educador. O status compreende a posição e o reconhecimento dos 
educadores na organização escolar e na rede de relações sociais que ela tenta regular. Enfim, a experiência, por definição subjetiva, é entendida aqui como o sentido que o educador constrói e compartilha com seu trabalho e sua profissão, as emoções geradas pelo trabalho, a "relação" entre sua atividade e seu status.

Para definir a dimensão experiência, várias expressões remetem a várias tradições disciplinares e teóricas: satisfação no trabalho, vivência profissional, engajamento profissional, motivação, investimento etc. Decidimos permanecer fiéis à expressão usada na obra sobre o trabalho educacional, "desempenho no trabalho" (CHARLOT et al., 1992, p. 152), tanto porque ela nos permite salientar a importância da relação entre o trabalhador e sua atividade, portanto na dimensão subjetiva do trabalho, quanto porque o trabalho engloba mais dimensões do que apenas aquela da tarefa.

A expressão de "desempenho em" se refere à relação entre um sujeito e um objeto e à sua qualidade. Esta podendo ser caracterizada de várias maneiras, seguindo diferentes critérios: sentido/sem sentido; satisfação/insatisfação; atividade/passividade; submissão/rebelião; positividade/negatividade; estima/ desprendimento; engajamento/retração etc. Essa expressão é usada por vários autores com orientações teóricas variadas (sociologia, psicanálise, formação de adultos). Por exemplo, Charlot et al. $(1992,1999)$ usaram essa expressão para dar conta da experiência escolar dos alunos de escolas primárias de periferias, de colégios de bairros e de liceus profissionalizantes. Para o autor, o desempenho do saber é "o desempenho de mundo, do outro, de si mesmo sobre um assunto confrontado à necessidade de aprender; o desempenho do saber é o conjunto (organizado) das relações que um assunto desenvolve com tudo o que obtém do 'aprender' e do 'saber'” (1999, p. 93-94). Certamente essa definição é muito ampla e engloba muitos fenômenos, mas após décadas de trabalhos de pesquisa inseridos no paradigma da reprodução social e, portanto centrados sobre o peso das estruturas, os trabalhos de Charlot et al. Tiveram o mérito de reorientar o esforço de compreensão do fracasso escolar em direção aos fenômenos de construção do sentido que os alunos dão à experiência escolar. Ela também obrigou os agentes escolares a reconhecerem a importância da subjetividade (i.e. sua característica de sujeito) do aluno.

Transposta ao mundo profissional do ensino, a noção de desempenho no trabalho remete à experiência subjetiva da profissão, no sentido de que seu exercício reviste o educador, segundo os desejos e os sonhos que o orientam, com as expectativas e aspirações profissionais, e também com a avaliação de sua realização, com as emoções engendradas pelo trabalho (prazer, frustração etc.), e com o balanço que o educador faz de seu investimento nessa atividade. Há, portanto, várias aberturas - afetiva, cognitiva e avaliativa - no desempenho no trabalho. Ele insere também o educador em uma temporalidade lhe permitindo se 
situar e almejar ou não um futuro profissional. Essa noção pode ser aproximada da noção "global" sobre o ensino.

Nós caracterizamos o trabalho educacional como um tipo de trabalho particular, com, em e para a humanidade, um trabalho interativo ou relacional representado por um número importante de profissões, ditas de relações humanas (trabalho social, terapias diversas, orientação, reeducação e reabilitação etc.). Nesse tipo de trabalho, são os trabalhadores da primeira linha que terminam a missão da instituição, interpretando-a conforme seus valores pessoais profissionais, com os instrumentos que estão ligados por um lado à sua personalidade (capacidade de persuasão, convicção, comunicação, sedução, manipulação, competências pedagógicas e didáticas etc.), e por outro ao difícil êxito em medir e que depende da vontade do outro, o "cliente" ou o usuário, de investir na sua própria realização. Essas profissões têm um forte componente ético porque concernem e implicam seres humanos, porque são atravessados por dilemas e contradições e porque as intenções dos agentes têm um papel determinante. Mesmo que sejam submissos, eles escapam à racionalização instrumental, ao mesmo tempo em que participam fortemente, a uma racionalidade comunicacional.

Em resumo, como indica a Figura 1, o desempenho no trabalho é o produto da satisfação que aqueles que o exercem obtêm a partir de três elementos: a experiência cotidiana de sua carga de trabalho, as condições de trabalho e a qualidade das relações com os diferentes agentes da escola (alunos, colegas, direção). Além disso, longe de ser estática, essa relação evolui no tempo de carreira e segundo as políticas educacionais e do contexto social, pois os elementos que a estruturam são eles próprios interligados e sujeitos a ajustes e reavaliações.

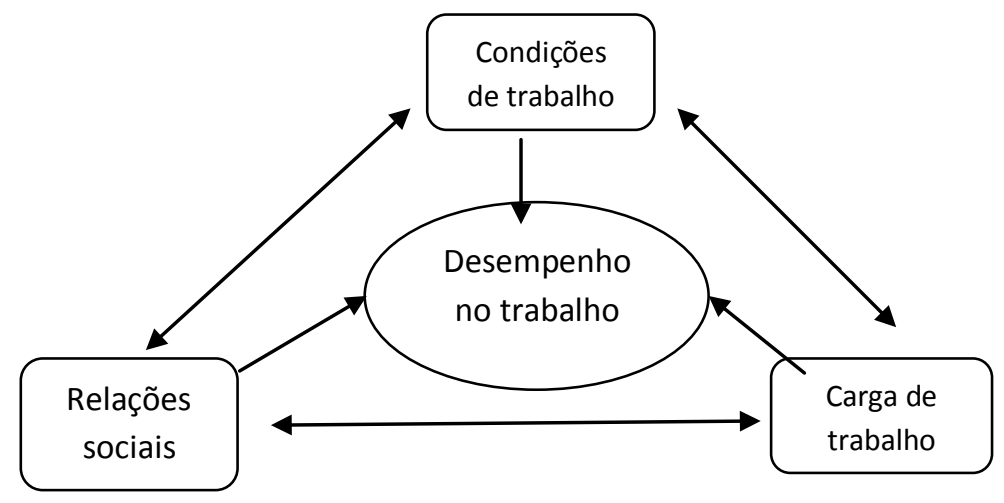

FIGURA 1 - OS FATORES QUE INFLUENCIAM O DESEMPENHO NO TRABALHO 
O objeto deste artigo é relacionar essas três dimensões a partir de uma análise secundária de uma pesquisa realizada em 2006 entre os educadores e profissionais não educadores canadenses. A análise repousa sobre a percepção que os educadores têm de sua tarefa, das condições de ensino, das relações entre os agentes concernentes e de seus status dentro da organização.

Nossos dados, de ordem quantitativa, não nos permitem explorar profundamente e de maneira exaustiva o desempenho dos educadores canadenses, mas temos elementos que permitem defini-lo parcialmente e nos autorizam a proceder a uma sondagem do balanço, das emoções e do apego ou do engajamento no trabalho dos educadores interrogados. Esses dados também nos permitem ligar diversos aspectos (percebidos) da tarefa, das condições de ensino, das relações entre os agentes e dos status dos educadores na organização escolar ao desempenho no trabalho.

\section{Metodologia}

Os dados utilizados neste artigo foram tirados de uma pesquisa pan-canadense feita em 2006 entre os educadores, profissionais não educadores e outros membros do pessoal das escolas primárias e secundárias das províncias e territórios do Canadá (2006) ${ }^{4}$. O objetivo visado pela pesquisa era recolher dados permitindo retratar um perfil global da profissão docente no Canadá: sua inserção profissional, suas condições de trabalho, sua percepção dos efeitos e das mudanças sociais e das políticas educativas sobre o exercício de sua profissão.

Objetivo alcançado, a análise se inclina unicamente sobre os dados recolhidos entre os docentes e em ligação com sua vivência profissional e suas condições de trabalho. Após a exclusão dos sujeitos sobre os quais faltam dados para as questões usadas retivemos uma amostra de 2.163 deles.

\section{Medida das variáveis}

A variável dependente estudada "desempenho no trabalho do educador" foi medida pelas respostas à pergunta sobre os diferentes aspectos da vivência profissional, por exemplo, a satisfação "global” sob o ponto de vista do educador,

4 Os dados estão disponíveis no site $<$ www.teachcan.ca $>$. Eles provêm de uma pesquisa subvencionada pelo Conselho de Pesquisa em Ciências Sociais e Humanas do Canadá, para o quadro do programa dos Grandes Trabalhos de Pesquisa Prevista. 
a conviç̧ão de ter feito a melhor escolha de carreira, o uso das capacidades intelectuais, o sentimento de valorização pessoal ou de frustração, a usura e a fadiga de trabalhar cotidianamente com os alunos etc. A questão compreendia sete itens em uma escala de resposta com seis modalidades indo de 1 (raramente) a 6 (com frequência). A análise fatorial exploratória mostrou que todos os itens se reagrupavam em torno de um único fator, sua contribuição fatorial (loading factor) variando de 0,59 a 0,80 (Quadro 1). O coeficiente Alpha de Cronbach $(\alpha=0,85)$ indica que a consistência dos itens é elevada.

Enquanto variável independente, levamos em consideração a satisfação com relação à carga e às condições de trabalho e à percepção das relações sociais em sala de aula e na escola. A exemplo de outras variáveis, procedemos às análises fatoriais cujos principais resultados (itens, fatores, contribuição fatorial e coeficiente Alpha de Cronbach) são igualmente apresentados no Quadro 1.

Para a satisfação no que se refere à carga de trabalho, foi pedido aos educadores que dissessem em que medida eles estavam satisfeitos com as diversas tarefas a fazer (por exemplo, o número de aulas a preparar, a supervisão dos alunos etc.) e com as características da sala (por exemplo, o número de alunos). A questão era constituída de seis itens, cada um compreendendo por sua vez uma escala de seis modalidades indo de 1 (insatisfeito) a 6 (satisfeito). A análise fatorial permitiu distinguir dois fatores. O primeiro "as tarefas de ensino" reagrupa oito itens cuja contribuição fatorial varia de 0,36 a 0,69 . O coeficiente Alpha de Cronbach $(0,80)$ revela que a consistência interna é elevada. O segundo fator "tarefas periféricas (administrativas)" é igualmente constituído de oito itens cuja contribuição fatorial varia de 0,53 a 0,73 . O Alpha de Cronbach $(0,86)$ indica também uma consistência interna elevada dos itens.

Sobre as condições de trabalho, os respondentes indicaram seu grau de satisfação em relação aos diversos aspectos da profissão (por exemplo, o salário e as vantagens sociais, o número de alunos por turma ou a autonomia profissional). Cada item compreendia igualmente uma escala de respostas a seis modalidades indo de 1 (insatisfeito) a 6 (satisfeito). Após a análise fatorial, identificamos duas dimensões (Quadro 1). A primeira, "satisfação em relação às condições materiais", reagrupa quatro itens cuja contribuição fatorial varia de 0,38 a 0,67 . O coeficiente Alpha de Cronbach é de 0,62. A segunda dimensão, "satisfação com relação ao status", é constituída de três itens, com uma contribuição fatorial variando de 0,39 a 0,84, sendo o Alpha de Cronbach de 0,70.

A percepção das relações sociais com os alunos foi medida pela questão em que os respondentes deveriam precisar seu grau de concordância com os enunciados sobre seu papel ou status face aos alunos (por exemplo, a autoridade, a aprendizagem ou o apoio). A escala de resposta compreendia seis modalidades indo de 1 (em desacordo) a 6 (de acordo). A análise fatorial permitiu isolar 
dois fatores. O primeiro, "relações gratificantes", compreende seis itens cuja contribuição fatorial varia de 0,49 a 0,75 . O Alpha de Cronbach $(0,75)$ revela que a consistência interna entre os itens é suficientemente elevada. O segundo fator, "relações difíceis", compreende cinco itens com uma contribuição fatorial variando de 0,38 a 0,55. Seu coeficiente de consistência interna é de 0,63.

Enfim, a percepção das relações sociais na escola foi medida por uma questão que convidava os respondentes a precisar o grau de satisfação com relação aos outros membros da equipe pedagógica (por exemplo, o diretor, os colegas). A questão compreendia itens com uma escala de respostas com seis modalidades indo de 1 (insatisfeito) a 6 (satisfeito). A análise fatorial permitiu identificar um único fator, a contribuição fatorial dos itens variou de 0,37 a 0,77 , enquanto que o coeficiente interno foi de 0,82 .

continua

\begin{tabular}{|l|r|}
\hline Fatores e itens & $\begin{array}{r}\text { Cont } \\
\text { fa }\end{array}$ \\
\hline Desempenho no trabalho $(\boldsymbol{\alpha}=\mathbf{0 , 8 5})$ & 0,80 \\
Estou farto de ensinar e de trabalhar com os alunos* & 0,76 \\
Penso em deixar o ensino* & 0,73 \\
O ensino me proporciona grandes satisfações & 0,73 \\
Eu ainda escolheria o ensino se devesse recomeçar minha vida & 0,71 \\
Sinto-me frustrado pelo ensino* & 0,60 \\
O ensino me permite usar o máximo das minhas capacidades & 0,59 \\
Poderia usar melhor minhas habilidades intelectuais em outra profissão* &
\end{tabular}

\section{Satisfação com relação à carga de trabalho}

Tarefas periféricas $(\alpha=0,86)$

Reuniões com o pessoal não educador $\quad 0,73$

$\begin{array}{ll}\text { Encontros pedagógicos com os colegas } & 0,69\end{array}$

$\begin{array}{ll}\text { Tarefas administrativas } & 0,67\end{array}$

Participação em diversos comitês ligados ao trabalho $\quad 0,64$

$\begin{array}{lr}\text { Apoio pedagógico a colegas } & 0,59\end{array}$

$\begin{array}{ll}\text { Encontros com os pais } & 0,56\end{array}$

Participação em atividades formais de formação $\quad 0,55$

Atividades para-escolares fora dos horários regulares $\quad 0,53$

QUADRO 1 - MATRIZ FATORIAL - FATORES E ITENS

NOTA: * para fins de análise, os escores desses itens foram invertidos. 
continuação

Fatores e itens

Tarefas de ensino $(\alpha=0,80)$

$\begin{array}{ll}\text { Planejamento e preparação do ensino } & 0,69\end{array}$

Número de preparação de aulas $\quad 0,67$

Avaliação dos trabalhos dos alunos $\quad 0,61$

Número de horas de ensino semanal $\quad 0,58$

$\begin{array}{ll}\text { Números de alunos em sala } & 0,48\end{array}$

Heterogeneidade na sala de aula $\quad 0,45$

Atendimento dos alunos fora dos horários de ensino $\quad 0,43$

Supervisão dos alunos fora dos horários de ensino $\quad 0,36$

\section{Satisfação com relação às condições de trabalho}

Condições materiais $(\alpha=0,62)$

$\begin{array}{ll}\text { Estado físico de sua(s) sala(s) } & 0,67\end{array}$

Disponibilidade do material e dos recursos para a turma $\quad 0,63$

Número de alunos na(s) sua(s) turma(s) $\quad 0,49$

$\begin{array}{ll}\text { Apoio técnico na escola } & 0,47\end{array}$

$\begin{array}{ll}\text { Salário e vantagens sociais } & 0,38\end{array}$

Status $(\alpha=0,70)$

$\begin{array}{ll}\text { Nível de responsabilidade na escola } & 0,84\end{array}$

$\begin{array}{ll}\text { Autonomia profissional } & 0,68\end{array}$

$\begin{array}{lr}\text { Possibilidade de promoção } & 0,39\end{array}$

Percepção das relações com os alunos

Relações gratificantes $(\alpha=0,75)$

Tenho o sentimento de ter um papel gratificante para meus alunos $\quad 0,75$

Ao fim de um dia de trabalho, tenho o sentimento que meus alunos apren- $\quad 0,71$ deram algo

Minha relação com meus alunos é primeiramente afetiva: gosto de lhes 0,67 ensinar

Vejo-me como uma pessoa que tem um importante impacto sobre o futuro $\quad 0,65$ dos alunos

Meus alunos respeitam minha autoridade $\quad 0,59$

$\begin{array}{ll}\text { Motivar meus alunos é fácil } & 0,49\end{array}$

QUADRO 1 - MATRIZ FATORIAL - FATORES E ITENS 
conclusão

\begin{tabular}{|c|c|}
\hline Fatores e itens & $\begin{array}{c}\text { Contribuição } \\
\text { fatorial }\end{array}$ \\
\hline \multicolumn{2}{|l|}{ Relações dificeis $(\alpha=0,63)$} \\
\hline $\begin{array}{l}\text { As necessidades de meus alunos são tão diferentes que tenho dificuldade } \\
\text { em atender }\end{array}$ & 0,55 \\
\hline Manter a disciplina com meus alunos me demanda muita energia & 0,56 \\
\hline Quando meus alunos estão agitados, sinto-me sobrecarregado & 0,53 \\
\hline $\begin{array}{l}\text { Alguns alunos têm problemas tão importantes a ponto de eu não poder } \\
\text { ajudá-los }\end{array}$ & 0,51 \\
\hline Às vezes, tenho medo de meus alunos & 0,38 \\
\hline \multicolumn{2}{|l|}{ Relações com os membros da equipe pedagógica $(\alpha=0,82)$} \\
\hline Representante da coletividade & 0,77 \\
\hline Agentes sociais intervindo na escola & 0,76 \\
\hline Empregados profissionais não educadores & 0,75 \\
\hline Pessoal auxiliar & 0,72 \\
\hline Pais & 0,63 \\
\hline Outros educadores & 0,51 \\
\hline Diretor da escola & 0,37 \\
\hline
\end{tabular}

QUADRO 1 - MATRIZ FATORIAL - FATORES E ITENS

\section{Resultados}

A percepção dos educadores com relação a sua profissão é muito variável. Se a maioria dos respondentes se agrada da profissão, é preciso reconhecer que as opiniões são compartilhadas. Na verdade, para alguns, o desempenho no trabalho é negativo. Quando agrupamos os respondentes que marcaram 1, 2 ou 3 sob o termo de "raramente", 4, 5 ou 6 sob o termo de "com frequência", os resultados da análise das respostas aos itens da questão sobre a vivência profissional (Quadro 2) mostram ao mesmo tempo uma tendência bastante positiva do conjunto, mas é importante a nuance à luz de zonas de insatisfação contudo significativas (entre 1/5 e 1/3 dos respondentes). Foi assim que uma parte dos educadores teve com frequência o sentimento de que o ensino não permite usar o máximo de suas capacidades $(33,1 \%)$, os que não pareceram inclinados em escolher novamente o ensino como carreira e, portanto, não estavam inclinados 
a confirmar sua escolha profissional $(33,2 \%)$, e os que pensam com frequência em deixar o ensino (23,6\%). Perto de $29 \%$ dos educadores pensam que poderiam usar melhor suas habilidades intelectuais em outra profissão. Notemos que 38,4\% dos respondentes se sentem frustrados pelo ensino, que $22,6 \%$ estão fartos de ensinar e de trabalhar com os alunos e que $17,8 \%$ estimam que o ensino não lhes proporcione grandes satisfações.

\begin{tabular}{|c|c|c|}
\hline Item & Raramente & Com frequência \\
\hline Sinto-me frustrado pelo ensino & $61,7 \%$ & $38,3 \%$ \\
\hline Estou farto de ensinar e de trabalhar com os alunos & $77,4 \%$ & $22,6 \%$ \\
\hline Penso em deixar o ensino & $76,4 \%$ & $23,6 \%$ \\
\hline $\begin{array}{l}\text { Sinto que o ensino me permite usar o máximo de } \\
\text { minhas capacidades }\end{array}$ & $33,1 \%$ & $66,9 \%$ \\
\hline $\begin{array}{l}\text { Poderia usar melhor minhas habilidades em outra } \\
\text { profissão }\end{array}$ & $71,3 \%$ & $28,7 \%$ \\
\hline O ensino me proporciona grandes satisfações & $17,8 \%$ & $82,2 \%$ \\
\hline $\begin{array}{l}\text { Eu ainda escolheria o ensino se devesse recomeçar } \\
\text { minha vida }\end{array}$ & $33,2 \%$ & $66,2 \%$ \\
\hline
\end{tabular}

QUADRO 2 - REPARTIÇÃO DOS RESPONDENTES SOBRE OS ITENS DE DESEMPENHO DO TRABALHO DO EDUCADOR

Quando examinamos o escore global dos itens levado a uma escala de 6 pontos, os resultados (Quadro 3) mostram que os educadores apresentam uma vivência profissional relativamente positiva, o escore médio $(4,31)$ sendo claramente abaixo do ponto médio $(3,5)$. Entretanto, o valor da variação-tipo indica que a situação é bastante variável entre os respondentes.

É interessante constatar que a média de 4,31 é mais elevada que a média da satisfação sobre a maior parte das variáveis independentes, salvo para as variáveis que medem o grau de satisfação dos educadores com respeito às relações com seus alunos. Foi assim que a satisfação com relação à carga de ensino foi bastante mitigada (média de 3,33), o mesmo que com relação aos membros da equipe pedagógica (média de 3,03). A satisfação com relação às condições materiais de trabalho não ultrapassa 3,56, ponto médio da escala. Salvo para as relações com os alunos, nenhuma outra variável independente atinge o limite de 4,00 de média, ainda que o nível de satisfação com relação ao status do ensino na escola (nível de responsabilidade, autonomia profissional, possibilidade de promoção) atinja quase que o mesmo patamar (média $=3,97$ ). Se dermos conta de um possível efeito de utilidade social, os respondentes tendo tendência a se mostrar mais satisfeitos do que na verdade são, pode-se pensar que sobre certos 
aspectos, principalmente no que se refere à carga de ensino, às relações sociais e às condições materiais, os educadores canadenses não são unânimes quanto à satisfação no trabalho.

Tudo se passa como se nossa medida do desempenho no trabalho testemunhasse uma satisfação "global" com relação ao ensino, mais ampla que várias dimensões particulares e específicas do trabalho, de suas condições e do contexto organizacional e relacional no qual o ensino se desenvolve. Isso merece ser aprofundado e faz pensar que o desempenho no trabalho ultrapassa certas dimensões particulares da profissão e que, em certas condições, os educadores podem se acomodar com uma situação de trabalho imperfeita não mais procurando deixar o ensino.

Examinamos o grau de correlação entre o desempenho no trabalho dos educadores e as variáveis independentes (satisfação com relação a diversas dimensões do trabalho, as suas condições, as suas relações sociais no meio escolar). De um modo geral, o desempenho no trabalho é significativamente correlacionado a cada uma dessas variáveis $(\mathrm{p}<0,001)$, principalmente às relações gratificantes $(\mathrm{r}=0,46)$ ou difíceis $(\mathrm{r}=0,43)$ com os alunos. Aliás, essas variáveis são correlacionadas entre si, mas o grau de correlação não é bastante forte para levantar uma colinearidade na análise multivariada. Notemos, no entanto, que a correlação entre a satisfação com relação às tarefas administrativas e a satisfação com relação às tarefas de ensino é uma exceção $(r=0,62)$.

\begin{tabular}{|c|c|c|c|c|c|c|c|c|c|c|}
\hline & (1) & (2) & (3) & (4) & (5) & (6) & (7) & (8) & Média & \begin{tabular}{|c|} 
Variação \\
- tipo \\
\end{tabular} \\
\hline $\begin{array}{l}\text { (1) Desempenho no } \\
\text { trabalho }\end{array}$ & 1,00 & - & - & - & - & - & - & - & 4,31 & 1,17 \\
\hline (2) Carga de ensino & $0,40^{*}$ & 1,00 & - & - & - & - & - & - & 3,33 & 1,07 \\
\hline (3) Tarefas periféricas & $0,34 *$ & $0,62^{*}$ & 1,00 & - & - & - & - & - & 3,65 & 1,17 \\
\hline (4) Condições materiais & $0,34 *$ & $0,55^{*}$ & $0,38^{*}$ & 1,00 & - & - & - & - & 3,56 & 1,17 \\
\hline (5) Status & $0,43^{*}$ & $0,47^{*}$ & $0,52 *$ & $0,50 *$ & 1,00 & - & - & - & 3,97 & 1,22 \\
\hline $\begin{array}{l}\text { (6) Relações gratifi- } \\
\text { cantes com os alunos }\end{array}$ & $0,48^{*}$ & $0,18^{*}$ & 0,20 * & $0,17 *$ & $0,25 *$ & 1,00 & - & - & 4,85 & 0,68 \\
\hline $\begin{array}{l}\text { (7) Relações difíceis } \\
\text { com os alunos }\end{array}$ & $0,42 *$ & $0,26^{*}$ & $0,16^{*}$ & $0,22 *$ & $0,22 *$ & $0,30 *$ & 1,00 & - & 3,03 & 1,01 \\
\hline $\begin{array}{l}\text { (8) Relações com os } \\
\text { membros da equipe } \\
\text { pedagógica }\end{array}$ & $0,36^{*}$ & $0,26^{*}$ & $0,39 *$ & $0,29 *$ & $0,47^{*}$ & $0,38^{*}$ & $0,23 *$ & 1,00 & 4,61 & 0,89 \\
\hline
\end{tabular}

QUADRO 3 - COEFICIENTE DE CORRELAÇÃO ENTRE O DESEMPENHO NO TRABALHO E AS VARIÁVEIS INDEPENDENTES

NOTA: $* \mathrm{p}<0,001$. 
Enfim, procedemos a uma análise de regressão múltipla para determinar a influência relativa das diferentes variáveis independentes (Quadro 4). No modelo 1, introduzimos as variáveis independentes sobre a carga de trabalho (tarefa de ensino e tarefas periféricas) como também sobre as condições materiais e o status do educador na organização escolar (autonomia e responsabilidade profissional). Como indicam os resultados, essas variáveis têm uma influência significativa e positiva sobre o desempenho no ensino. Quanto mais elevada a satisfação pelas condições e pela carga de trabalho, mais positiva é a percepção dos respondentes sobre sua profissão. O desempenho no trabalho tem a tendência em melhorar entre os educadores que estão satisfeitos com sua tarefa de ensino e com seu status no meio escolar. A variação explicada pelo modelo é relativamente elevada (23\%). Perto de um quarto da variante ligada ao desempenho no trabalho é explicada por essas variáveis. Lembremos que essas variáveis estão no coração das reivindicações sindicais dos educadores. Nossos dados revelam que fazendo a promoção da melhoria dessas dimensões, as associações sindicais canadenses (principalmente a Federação Canadense dos Educadores) aparecem em diapasão com o ponto de vista de seus membros.

Ao modelo 2, nós acrescentamos as variáveis ditas relacionais, as que concernem as relações com os alunos e os outros membros da equipe pedagógica. A introdução dessas variáveis diminui a influência associada às condições e à carga de trabalho, que permanece, no entanto, significativa. Os resultados indicam que a qualidade das relações com os alunos e com os outros membros da equipe pedagógica tem uma influência positiva sobre o desempenho no trabalho dos educadores. Como podíamos antecipar, o desempenho é claramente positivo entre aqueles que consideram que suas relações com os alunos são gratificantes. Por outro lado, aqueles que têm o sentimento de viver relações difíceis com os alunos têm tendência a ter uma imagem negativa de sua profissão. Notemos que o acréscimo dessas variáveis ao modelo contribui para aumentar de maneira evidente a variação explicada, passando de $23 \%$ a $41 \%$.

No modelo 3 , controlamos as variáveis sociodemográficas e contextuais conhecidas por sua influência sobre o desempenho no trabalho dos educadores. Os resultados revelam que somente três dessas variáveis exercem uma influência significativa sobre o desempenho do educador: o gênero, a experiência profissional e a região. $\mathrm{O}$ resultado é relativamente mais positivo para as mulheres do que para os homens; e tem tendência a ser negativo entre aqueles que são mais antigos no trabalho: diríamos que quanto mais o tempo passa, mais o exercício da profissão se torna menos gratificante. Comparados àqueles das províncias atlânticas (categorias de referência), os educadores da Região das Pradarias (Manitoba, Saskatchewan e Alberta) e da Colômbia-Britânica parecem mais críticos que os outros com relação à profissão. Isso se dá provavelmente pelo 
fato de políticas educativas recentes terem sido implantadas nas províncias do Oeste do Canadá e que foram traduzidas por enfrentamentos maiores com os educadores e suas associações sindicais (LESSARD; BRASSARD, 2006). Constata-se também que a ordem de ensino (fundamental ou médio) e o meio socioeconômico da escola não influenciam o desempenho dos educadores, uma vez que as outras variáveis são levadas em conta pelo modelo 3. Isso faz pensar que o desempenho no trabalho não é significativamente mais negativo no ensino médio do que no fundamental, nem nas escolas de meios desfavorecidos se comparadas às outras. Essas variáveis sociodemográficas e contextuais contribuem ligeiramente apenas para a eficácia do modelo, não explicando mais que $1 \%$ da variação.

No total, as variáveis integradas ao modelo 3 explicam $42 \%$ da variação do desempenho dos educadores canadenses, o que é bastante satisfatório. Quando observamos os coeficientes das variáveis do modelo 3 , constatamos que os coeficientes mais elevados são próprios das variáveis que medem a qualidade das relações gratificantes $(0,28$ e 0,23$)$ ou difíceis $(-0,23$ e - 0,24$)$ entre os educadores e os alunos. Seguem os coeficientes do status dos educadores $(0,27$ e 0,19$)$ e da tarefa de ensino $(0,19$ e 0,13$)$. É interessante constatar que, no modelo 3 , as relações com os outros membros da equipe pedagógica permanecem fortemente significativas $(0,07)$, enquanto que as condições materiais $(0,06)$ perdem sua importância com relação às outras variáveis.

\begin{tabular}{|c|c|c|c|}
\hline & Modelo 1 & Modelo 2 & Modelo 3 \\
\hline \multicolumn{4}{|l|}{ Variáveis independentes } \\
\hline \multicolumn{4}{|l|}{ Carga de trabalho } \\
\hline Tarefas de ensino & $0,19 * * *$ & $0,12 * * *$ & $0,13 * * *$ \\
\hline Tarefas periféricas & 0,05 & 0,03 & 0,01 \\
\hline \multicolumn{4}{|l|}{ Condição de trabalho } \\
\hline Condições materiais & $0,07 * *$ & $0,06^{*}$ & $0,05^{*}$ \\
\hline Status & $0,27 * * *$ & $0,19 * * *$ & $0,19 * * *$ \\
\hline \multicolumn{4}{|l|}{ Relação com os alunos } \\
\hline Relações gratificantes & - & $0,28 * * *$ & $0,29 * * *$ \\
\hline Relações difíceis & - & $-0,23 * * *$ & $-0,24 * * *$ \\
\hline Relações com os membros da equipe pedagógica & - & $0,07 * *$ & $0,07^{* *}$ \\
\hline
\end{tabular}

QUADRO 4 - COEFICIENTES DE REGRESSÃO LINEAR 
conclusão

\begin{tabular}{|l|c|c|c|}
\hline & Modelo 1 & Modelo 2 & Modelo 3 \\
\hline Variáveis de controle & & & \\
Gênero (feminino) & - & - & $0,04 *$ \\
Idade & - & - & $-0,03$ \\
Experiência profissional & - & - & $-0,09 *$ \\
Ordem de Ensino (Fundamental) & - & - & 0,01 \\
Meio desfavorecido & - & - & 0,01 \\
Região & & & \\
Ontário & - & - & 0,01 \\
Québec & - & - & $-0,04$ \\
pradarias & - & - & $-0,07 * *$ \\
Colômbia - Britânica & - & - & $-0,07 * *$ \\
$\mathrm{R}^{2}$ ajustado & 0,23 & 0,41 & 0,42 \\
F & $163,24 * * *$ & $158,86 * * *$ & $75,43 * * *$ \\
$\mathrm{~N}$ & 2.159 & 1.618 & 1.618 \\
\hline
\end{tabular}

QUADRO 4 - COEFICIENTES DE REGRESSÃO LINEAR

NOTA: * $\mathrm{p}<0,05 ; * * \mathrm{p}<0,01 ; * * * \mathrm{p}<0,001$.

\section{Conclusão}

O presente artigo teve por objetivo examinar os fatores que influenciam o desempenho no trabalho dos educadores canadenses, assim como sua importância relativa. Segundo a análise dos trabalhos sobre a questão, ele seria influenciado mais pelos fatores "intrínsecos" que "extrínsecos" dentre aqueles ligados à qualidade das relações com os alunos, com a direção e com os colegas do que os elementos associados às condições "materiais" ou de emprego.

Análise dos dados pronta, escolhemos examinar a influência da carga de trabalho (tarefa de ensino e tarefas periféricas), das condições (condições materiais e status) e das relações sociais em meio à equipe pedagógica (com os alunos, com outros membros da equipe). De modo geral, os resultados obtidos mostram que o desempenho no trabalho dos educadores está associado de maneira significativa à carga de trabalho e às condições de trabalho, mas também de igual maneira às relações sociais que cercam o exercício cotidiano da profissão.

$\mathrm{O}$ exame atento dos resultados nos leva a concluir que a influência das relações sociais é mais importante que as condições de trabalho. Mais particularmente, as relações com os alunos é que exercem uma influência claramente 
mais elevada que as outras variáveis: quanto mais essas relações são gratificantes, ao menos segundo a visão dos educadores, mais eles têm a tendência de atribuir um desempenho positivo a seu trabalho. Por outro lado, as relações difíceis com os alunos têm um efeito nefasto sobre a vivência profissional dos educadores. O mesmo ocorre, ainda que em menor grau, com a qualidade das relações com os outros membros da equipe pedagógica.

A contribuição principal deste artigo é dupla. Primeiramente, ele permite mostrar que qualquer política que vise à melhoria da condição educacional deveria priorizar as medidas de aprimoramento das relações com os alunos e das relações sociais no estabelecimento. Em segundo lugar, tal política passaria igualmente pela melhoria da carga de trabalho e das condições de trabalho, sobretudo pela valorização do status dos educadores, de sua autonomia e de sua responsabilidade profissional. Isso deveria normalmente se traduzir em uma participação mais ampla e melhor reconhecida dos educadores nas decisões concernentes ao trabalho e sua organização no estabelecimento escolar.

Em outro nível, nossos resultados confirmam o caráter central da relação com os alunos no desempenho dos educadores, o que é típico das profissões de relações humanas que só se realizam em, com e para os seres humanos (TARDIF; LESSARD, 1999).

\section{REFERÊNCIAS}

BARRÈRE, A. Les enseignants au travail. Routines incertaines. Paris: L'Harmattan, 2002. (Coll. Savoir et Formation).

BARTLETT, L. No Room. No Pay. No Time. Teachers' Work in a Time of Expanding Roles: A Contribution to Overwork Theory. Working paper, n. 47, Center for working families, University of California Berkeley, 2002.

BOUMARD, P. Métier impossible. La situation morale des enseignants. Paris: ESF, 1992.

BOURDONCLE, R.; DEMAILLY, L. Les professions de l'éducation et de la formation. Villeneuve-d'Ascq. Presses Universitaires du Septentrion, les métiers de la formation. 1998, p. 7-24.

CHARLOT, B.; BAUTIER, É.; ROCHEX, J-.Y. École et Savoir dans les banlieues... et ailleurs. Paris: Armand Colin, 1992. (Coll. Formation des enseignants). 
CHARLOT, B. Du Rapport au Savoir, Éléments pour une théorie. Paris: Anthropos. 1997.

CHARLOT, B. Le rapport au savoir en milieu populaire. Paris: Anthropos, 1999.

DUBET, F. Sociologie de l'expérience. Paris: Seuil, 1994.

FEDERAÇÃO CANADENSE DAS EDUCADORAS E EDUCADORES. The Economics of Teaching. Personal Financial comitment, Salary Comparisons, Taxation Issues. Economic Services Bulletin, June 2001-1. Cette étude a été reprise en 2005.

HÉLOU, C.; LANTHEAUME, F. Les difficultés au travail des enseignants: exception ou part constitutive du métier?, Recherche et Formation, n. 57, p. 65-78, 2008.

INGERSOLL, R. M. Teacher Turnover and Teacher Shortages: An Organisational Analysis. American Educational Research Journal, 38, 3, p. 499-534, 2001.

JOHNSON, S. M BERG, J. H.; DONALDSON, M. L. Who Stays in Teaching and Why: A Review of the Literature on Teacher Retention, NRTA, 2005. 129 p.

KAMANZI, C.; LESSARD, C.; BLAIS, J.-G.; RIOPEL, M.-C.; LAROSE, F.; TARDIF, M.; WRIGHT, A.; BOURQUE, J. Les enseignants et les enseignantes du Canada : contexte, profil et travail. Relatório de pesquisa. Grandes Trabalhos de Pesquisa do Conselho Canadense da Pesquisa em Ciências Sociais : evolução atual do pessoal do ensino fundamental e médio no Canadá, 2007.

KING, A. J. C.; PEART, M. J. Le personnel enseignant au Canada. Travail et qualité de vie. Ottawa : Fédération canadienne des enseignantes et enseignants, 1992.

LANTHEAUME, F. L'activité enseignante entre prescription et réel: ruses, petits bonheurs, souffrance, Éducation et Sociétés, n. 19, p. 67-81, 2007.

LESSARD, C.; BRASSARD, A. (Coll.). La « gouvernance » de 1'éducation au Canada: tendances et significations, Éducations et Sociétés. Revue Internationale Francophone de Sociologie de l'Éducation, 2, p. 181-201, 2006.

MAROY, C. L'enseignement secondaire et ses enseignants. Paris: De Boeck, 2002. p. 121-169 (Coll. Pédagogies en développement).

MAROY, C. Les évolutions du travail enseignant en France et en Europe : facteurs de changement, incidences et résistances dans l'enseignement secondaire. Revue Française de Pédagogie, n. 155, p. 111-142, 2006.

MASLACH, C.; JACKSON, S. E. Maslach Burnout Inventory Manual. Palo Alto, CA : Consulting Psychologists Press, 1986. 
MULFORD, B. Balance and learning: Crucial elements in leadership for democratic schools. Leadership and Policy in Schools. 2(2), 109-124. 2003.

OCDE. Organisation de coopération et développement économique. Le rôle crucial des enseignants : Attirer, former et retenir des enseignants de qualité. Paris : Direction de l'éducation, OCDE, 2005, 265 p.

PERRENOUD, P. La pédagogie à l'école des différences. Paris : ESF, 1995.

PERRENOUD, P. Pédagogie différenciée : des intentions à l'action. Paris : ESF, 1997.

PROST, A. L'enseignement en France, 1900-1967. Paris : Armand Colin, 1968.

TARDIF, M.; LESSARD, C. Le travail enseignant au quotidien, contribution à l'étude du travail dans les métiers et les professions d'interactions humaines, Québec : Presses de l’Université Laval, 1999.

Texto recebido em janeiro de 2010.

Texto aprovado em junho de 2010. 